\title{
Genetic Architecture of Fusarium Head Blight Resistance in Four Winter Triticale Populations
}

\author{
R. Kalih, H. P. Maurer, and T. Miedaner
}

State Plant Breeding Institute, University of Hohenheim, 70593 Stuttgart, Germany.

Accepted for publication 4 September 2014.

\begin{abstract}
Kalih, R., Maurer, H. P., and Miedaner, T. 2015. Genetic architecture of Fusarium head blight resistance in four winter triticale populations. Phytopathology 105:334-341.

Fusarium head blight (FHB) is a devastating disease that causes significant reductions in yield and quality in wheat, rye, and triticale. In triticale, knowledge of the genetic architecture of FHB resistance is missing but essential due to modern breeding requirements. In our study, four doubled-haploid triticale populations $(N=120$ to 200$)$ were evaluated for

tance were detected across all populations; six of them were derived from rye genome and located on chromosomes $4 \mathrm{R}, 5 \mathrm{R}$, and $7 \mathrm{R}$, which are here reported for the first time. The total cross-validated ratio of the explained phenotypic variance for all detected QTL in each population was 41 to 68\%. In all, 17 QTL for plant height and 18 QTL for heading stage were also detected across all populations; 3 and 5 of them, respectively, were overlapping with QTL for FHB. In conclusion, FHB resistance in triticale is caused by a multitude of QTL, and pyramiding them contributes to higher resistance.
\end{abstract} resistance to FHB caused by artificial inoculation with Fusarium culmorum in four environments. DArT markers were used to genotype triticale populations. Seventeen quantitative trait loci (QTL) for FHB resis-
Additional keywords: QTL mapping, Triticosecale.
Hexaploid triticale ( $\times$ Triticosecale Wittm.) is an intergeneric hybrid created by crossing the tetraploid female parent wheat (Triticum spp.) and the diploid male parent rye (Secale cereale L.), resulting in a genomic constitution of $2 n=6 x=42$ and the genome formula AABBRR (36). Secondary triticale were developed in the past by crossing primary triticale with each other and selecting early, high-yielding progeny. The modern varieties of triticale combine the high yield potential and good grain quality from wheat with winter hardiness and adaptation to unfavorable soils from rye (50). Triticale is now cultivated on about 3.2 million ha in Europe in 2012 (14); the main producers are Poland, Belarus, Germany, and France, with $76 \%$ of the total European triticale acreage. Although the main objective of triticale development was the use in human diet, today this crop is a valuable source of livestock feed due to its favorable composition of amino acids and high protein content (42). Additionally, triticale has shown great potential in biomass production $(19,40)$. In early times, triticale was totally resistant to biotrophic pathogens. However, expanding triticale cultivation area increased the selection pressure on these pathogen populations for virulent races and, today, triticale is readily infected by powdery mildew and yellow and leaf rust $(38,50)$. For diseases caused by necrotrophic pathogens, such as Stagonospora nodorum blotch, Septoria tritici blotch, or Fusarium head blight (FHB), triticale was always an accessible host.

FHB, caused by Fusarium graminearum, F. culmorum, and other Fusarium spp., is a widespread destructive disease and causes a major problem in production of wheat, rye, and triticale (33). The main concern about FHB infection in Europe goes beyond losses in grain yield and quality to the contamination by myco-

Corresponding author: T. Miedaner; E-mail address: miedaner@uni-hohenheim.de

* The $\boldsymbol{e}$-Xtra logo stands for "electronic extra" and indicates that the online version contains six supplementary tables.

http://dx.doi.org/10.1094/PHYTO-04-14-0124-R

(C) 2015 The American Phytopathological Society toxins such as deoxynivalenol, zearalenone, and nivalenol, which can harmful to human and animals. For managing FHB in cereals, classical approaches were applied such as crop rotation, appropriate soil cultivation, and fungicide application (7). However, even the most effective fungicide reduced FHB index across environments or applications, on average, by a maximum of $50 \%$ (7). Therefore, an integrated management strategy should be followed to control FHB, with growing more resistant cultivars as an important feature.

Generally, triticale is less susceptible to FHB than wheat and similarly susceptible as rye. Losses of up to $48 \%$ were reported for kernel weight per spike by artificial inoculation (38). FHB resistance is quantitatively inherited in wheat, rye, and triticale, with a continuous distribution among progeny showing mainly additive gene action $(5,37)$. Moreover, a high importance of genotype-environment interaction was reported in FHB infection in triticale (38), reflecting the need of testing across several environments (locations and years). Detecting new sources of resistance that can be introduced in current breeding programs constitutes a fundamental step in resistance breeding (52). Although an enormous number of quantitative trait loci (QTL) for FHB resistance in wheat was published $(2,8,28)$, only one QTL study in triticale (25) and none in rye is known.

Considerable improvement in modern genomic approaches in triticale led to the construction of a consensus genetic linkage map based on six populations (1). Based on this map, our objectives were to study the inheritance of FHB resistance in four of these doubled-haploid (DH) winter triticale populations and to analyze the colocalization of FHB QTL with other agronomic traits known to be correlated with FHB index such as plant height and heading stage.

\section{MATERIALS AND METHODS}

Plant materials and field trial. Four DH biparental mapping populations were used in this study: A (Modus/Saka3006, $N=$ 131), B (Modus/Saka3008, $N=120$ ), C (HeTi 117-06/Pawo, $N=$ 
200), and D (HeTi 117-06/Pigmej, $N=200)$. 'Pigmej' and 'Pawo' are cultivars originating from Poland and 'Modus', 'SAKA 3006', 'SAKA 3008', and 'HeTi 117-06' are from Germany. Pigmej has been released by the European Union variety list, Modus by the German variety list (9), and the other parents are breeding lines. $\mathrm{DH}$ populations were produced either by maize pollination (A and B) or by microspore culture (C and D).

Field experiments of the four populations (A, B, C, and D) were performed at two locations: Hohenheim $(\mathrm{HOH})$ (longitude $9^{\circ} 11^{\prime} 24^{\prime \prime} \mathrm{E}$, latitude $48^{\circ} 42^{\prime} 54^{\prime \prime} \mathrm{N}$, altitude $404 \mathrm{~m}$ ) and Oberer Lindenhof (OLI) (longitude $9^{\circ} 18^{\prime} 17^{\prime \prime} \mathrm{E}$, latitude $48^{\circ} 28^{\prime} 25^{\prime \prime} \mathrm{N}$, altitude $702 \mathrm{~m}$ ) across 2 years (2011 and 2012). All mapping populations were evaluated in field trials with common checks and, in 2011 and 2012, trials were split into two trials per location (first trial comprising mapping populations $\mathrm{A}$ and $\mathrm{B}$ and second trial comprising mapping populations $\mathrm{C}$ and $\mathrm{D}$ ). All trials were linked with several common checks, including the six parental lines of the four mapping populations. The experimental designs were $\alpha$ designs with three replications and incomplete blocks within each replication (24). Entries were planted in one-row plots of $1.2 \mathrm{~m}$ in length, $0.38 \mathrm{~m}$ in width between rows, and seed density of 30 kernels/row. The plots were treated with fertilizers, herbicides, and, if necessary, growth regulators according to standard agronomic practices at the respective locations.

Inoculum production, inoculation, and trait assessment. A highly aggressive single-spore isolate of Fusarium culmorum, FC46 ( = IPO 39-01) (46), was used to estimate FHB resistance by applying artificial inoculation in all environments. It should be noted that the resistance of wheat cultivars to $F$. culmorum and $F$. graminearum is highly correlated (31). Inoculum production was performed as previously described in detail by Miedaner et al. (32). Conidia suspension with a concentration of $7 \times 10^{5}$ spores $/ \mathrm{ml}$ was sprayed using an agricultural field sprayer (Hege 75, Waldenbuch, Germany) and an air pressure of 3 bars. Due to the differences in flowering time between genotypes and in order to make sure that each genotype was inoculated at least once at midanthesis stage, inoculation started with the beginning of flowering of early genotypes and was repeated three times within a period of 6 to 7 days in all environments. Disease severity was visually rated as percentage of infected spikelets per plot (0 to 100\%) representing FHB index. Rating for all genotypes was done at three dates: 21 to 25 days after inoculation (dpi), 25 to $29 \mathrm{dpi}$, and 29 to $33 \mathrm{dpi}$, depending on disease development in the individual environment (location-year combination). For further calculations, we used the average of all three ratings. Additionally, two agronomic traits related to FHB infection were evaluated. Heading stage was recorded at an optimal date in terms of the respective growth stage (EC) of each plot from EC 50 (very beginning of heading: Inflorescence starts opening the flag leaf but is still not visible) to EC 59 (end of heading: Inflorescence fully emerged) according to Anonymous (3). Plant height (in centimeters) was measured once after flowering in all environments.

Phenotypic data analysis. Evaluation of FHB resistance is always under the risk to prefer late genotypes which show better performance for FHB resistance because of the negative correlation between FHB and heading or flowering date $(13,26)$. To avoid this issue, we corrected the means of the genotypes according to their association with heading stage on each location separately following the recommended methods (13). These headingstage-corrected FHB data were used for all statistical analyses. The following statistical model was applied: $y_{i j k n o p}=\mu+g_{i}+l_{j}+$ $y_{k}+(c l)_{i j}+(c y)_{i k}+(g l)_{i j}+(g y)_{i k}+(l y)_{j k}+(c l y)_{i j k}+(g l y)_{i j k}+t_{p}+$ $r_{j k n p}+b_{j k n o p}+e_{i j k n o p}$, where $y_{i j k n o p}$ was the phenotypic observation for the $i$ th genotype at the $j$ th location in the $k$ th year of the $n$th replicate in the oth incomplete block in the $p$ th trial; $\mu$ was an intercept term; $c_{i}$ was a factor with a single level for each $\mathrm{DH}$ population and all check genotypes; $g, l$, and $y$ denote the effects of genotype, location, and year, respectively; and $c l, c y, g l, g y, l y$, cly, and gly denote the respective interaction effects. The effect of the $p$ th trial was $t_{p}$. Additionally, $r$ and $b$ as effects of replicate and incomplete block, respectively, within the $p$ th trial were included in the model and $e_{i j k n o}$ was the residual. Dummy variables were used to separate checks and genotypes and estimate variances for each group following Piepho et al. (39) but, for the sake of simplicity, we suppressed dummies in the model stated above. Variance components were determined by the restricted maximum likelihood (REML) method considering all effects as random. Error and block variances were assumed to be heterogeneous among trials and locations. Significance of variance component estimates was tested by model comparison with likelihood ratio tests in which halved $P$ values were used as an approximation (48). Heritability $\left(h^{2}\right)$ on an entry-mean basis was estimated from the variance components as the ratio of genotypic to phenotypic variance following the formula (15) $h^{2}=\sigma_{\mathrm{g}}^{2} /\left(\sigma_{\mathrm{g}}^{2}+\sigma_{\mathrm{gl}}^{2} / L+\sigma_{\mathrm{gy}}^{2} /\right.$ $Y+\sigma_{\text {gly }}^{2} / L Y+\sigma_{\mathrm{e}}^{2} / L Y R$, where $\sigma_{\mathrm{g}}^{2}$ denotes the genotypic variance, $\sigma_{\mathrm{gl}}^{2}$ the genotype-location interaction variance, $\sigma_{\mathrm{gy}}^{2}$ the genotype-year interaction variance, $\sigma_{\text {gly }}^{2}$ the genotype-location-year interaction variance, and $\sigma_{\mathrm{e}}^{2}$ the error variance; and $\mathrm{L}, \mathrm{Y}$, and $\mathrm{R}$ are the numbers of locations, years, and replications, respectively. Best linear unbiased estimates (BLUEs) were estimated across environments assuming fixed effects for the genotype $g_{i}$. Simple phenotypic correlation coefficients $(r)$ were calculated among all traits based on BLUEs of the DH lines. Significance of $r$ was tested by using tabulated values based on Fisher's (16) $z$ transformation. All statistical analyses were performed using ASReml 3.0 (18) and R (41).

Genotypic data analysis. All triticale lines were genotyped by DArT markers and the map positions of a high-density consensus linkage map were used for QTL analyses (1). For constructing this consensus map, six populations were used; four of them were the same as in this study. Pigmej is described by Alheit et al. (1) as 'TIW671'. A detailed description of the DNA extraction and marker analyses has been published elsewhere (1). QTL analysis based on composite interval mapping, implemented in software PlabMQTL (49), with a multiple regression approach (22), was used to detect QTL positions and effects. The appropriate number of cofactors and the final genetic model were chosen through stepwise regression on the basis of the smallest values of the modified Bayes Information Criterion (6). Critical logarithm of odds (LOD) thresholds were determined for each trait empirically according to Churchill and Doerge (11) using 10,000 permutation runs. Depending on the trait, we applied appropriate LOD thresholds, which corresponded to genome-wide error rates of $\alpha \leq$ 10,5 , and $1 \%$. The proportion of $\sigma_{\mathrm{g}}^{2}$ explained by the regression model was calculated as $p_{G}=R_{a d j}^{2} / h^{2}$, where $R_{a d j}^{2}$ is the adjusted proportion of phenotypic variance explained by the model. For the detected QTL, a 1-LOD support interval was specified around each QTL and a 95\% confidence interval was calculated after Darvasi and Soller (12). Additionally, to determine the bias of $R_{a d j}^{2}$ explained by detected QTL, fivefold cross validation was performed as follows. The entire data set was split into five genotypic subsamples, and means from four of five subsamples were used as an estimation set (ES) for QTL detection, localization, and estimation of genetic effects. The remaining data group was considered as the test set, in which predictions derived from the ES were tested for their validity by correlation of predicted and observed data. Out of this analysis, we give the frequency of recovery (i.e., the percentage of validation runs detecting the respective QTL).

\section{RESULTS}

Phenotypic data analysis. Disease development in four winter triticale populations was successfully attained at all four environments (Table 1). All genotypes were phenotyped for FHB severity, heading stage, and plant height across all environments. The 
phenotypic distribution of FHB index in four DH populations was approximately normal (Fig. 1); FHB means of DH populations varied only slightly, ranging from 23.6 to 30.3 (Table 2). Means of parents did not differ much in all populations except in population B, with 9\% higher FHB resistance of Modus. Parental means were close to the means of DH progenies across environments (Table 2). Mean plant height of $\mathrm{DH}$ populations ranged from 98.8 to $114.6 \mathrm{~cm}$, whereas means for heading stage were comparably close (Supplementary Table 1 ). Genotypic variances significantly $(P<0.001)$ larger than zero were observed for FHB index in all populations (Table 3 ). Population B recorded highest genotypic variation (53.15) and population $C$ the lowest (16.25). Variances due to genotype-location and genotype-year interactions were also significant for populations $\mathrm{A}, \mathrm{B}$, and $\mathrm{D}$; in populations $\mathrm{C}$, no significant interaction variances were recorded (Table 3). Estimated values for error variances in populations A and $\mathrm{B}$ were similar and almost doubled compared with the values of population $\mathrm{C}$ and $\mathrm{D}$. Genotypic variances were also significant $(P<0.001)$ for plant height and heading stage in all populations.
Entry mean heritability estimates for FHB ranged from 0.80 to 0.86 (Table 3 ) and were even higher for plant height and heading stage $\left(h^{2}>0.88\right)$.

FHB index and plant height were negatively correlated in all populations (Table 4); the highest correlations were observed in populations $\mathrm{C}$ and $\mathrm{D}(r>-0.7, P<0.001)$. For heading stage, only populations $\mathrm{C}$ and $\mathrm{D}$ were significantly $(P<0.001)$ correlated with FHB (Table 4).

QTL analyses. In this study, 17 QTL for FHB resistance were detected localized on 10 chromosomes in the triticale genome (Fig. 2). Ten QTL for FHB resistance had coefficients of determination $\left(R_{a d j}^{2}\right)>10 \%$ and, therefore, were regarded as major QTL (Supplementary Tables 2 to 5). The total of explained phenotypic variance for FHB in each population ranged from $41.1 \%$ in population A to $67.5 \%$ in population B. Some FHB resistance QTL on chromosomes 2B, 3B, 4R, and $5 \mathrm{R}$ were overlapping among two populations. All detected QTL in populations A and B were major QTL, with the highest ratio for the total explained genotypic variance found for population B (67.5\%) (Table 4).

TABLE 1. Means of Fusarium head blight (FHB) index (\%) of four doubled-haploid (DH) populations tested in four environments

\begin{tabular}{|c|c|c|c|c|c|}
\hline \multirow[b]{2}{*}{ Population } & \multirow[b]{2}{*}{$N^{\mathrm{a}}$} & \multicolumn{2}{|c|}{2011} & \multicolumn{2}{|c|}{2012} \\
\hline & & $\mathrm{HOH}$ & OLI & $\mathrm{HOH}$ & OLI \\
\hline A: Modus/Saka3006 & 131 & 26.8 & 26.4 & 17.4 & 26.1 \\
\hline B: Modus/Saka3008 & 120 & 29.0 & 28.9 & 22.1 & 26.8 \\
\hline D: HeTi 117-06/Pigmej & 200 & 18.0 & 17.2 & 22.6 & 28.0 \\
\hline
\end{tabular}

${ }^{a}$ Number of DH lines.

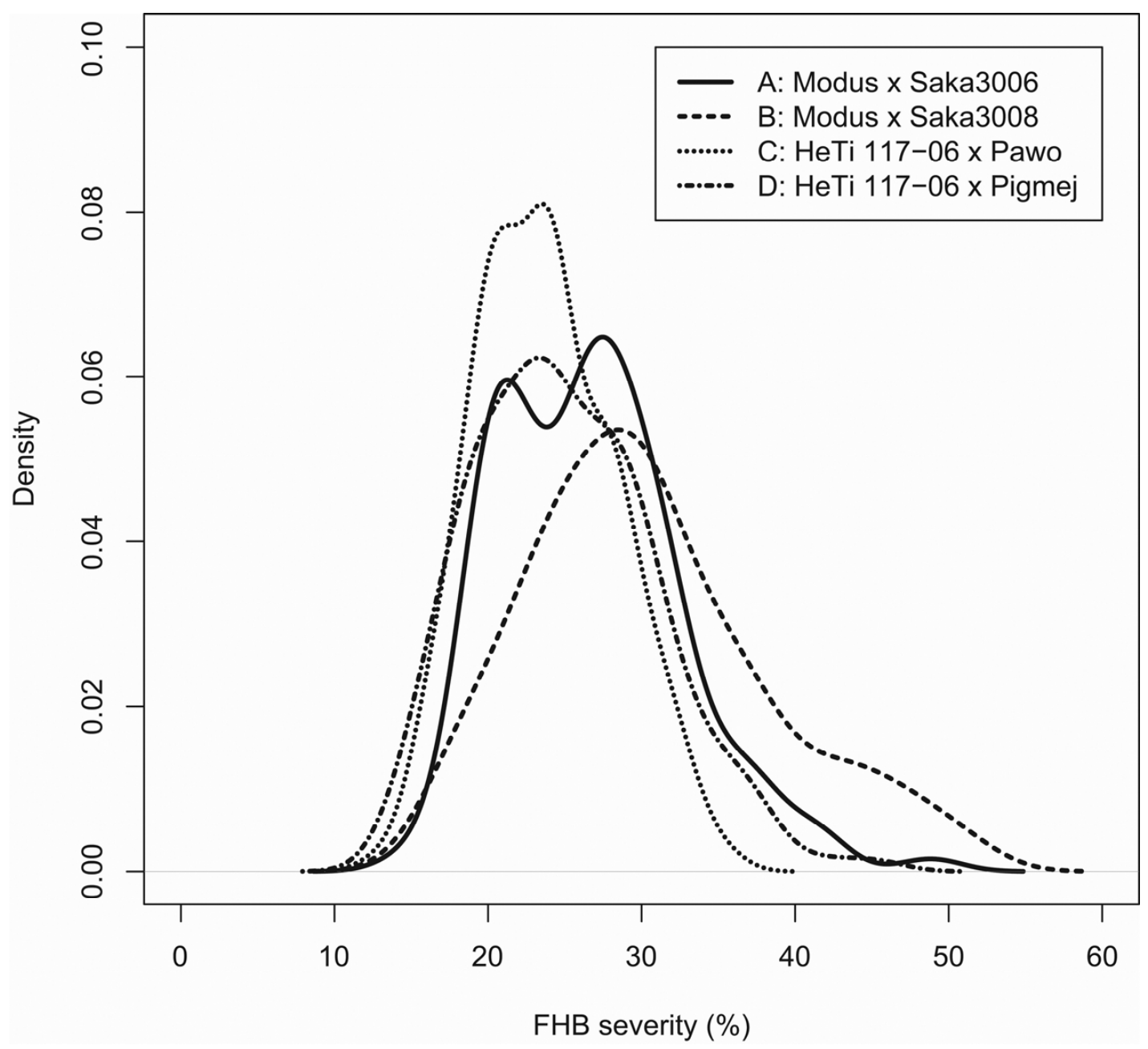

Fig. 1. Distribution of Fusarium head blight index in four populations. 
In population $\mathrm{B}$, a large FHB resistance QTL $\left(R^{2}=35 \%\right)$ colocalized with a major QTL for heading stage $\left(R_{a d j}^{2}=17 \%\right)$ on chromosome 4R (Supplementary Table 3). In population C, a major resistance QTL on chromosome 6A was found explaining 42,58 , and $36 \%$ of phenotypic variation for FHB index, plant height, and heading stage, respectively (Supplementary Table 4). Further, another major QTL for FHB resistance on chromosome $5 \mathrm{R}$ was detected in population $\mathrm{D}$ with the highest additive effect (Supplementary Table 5). This QTL also significantly affected plant height and heading stage, representing the rye-derived dwarfing gene $D d w 1$ recently described to occur in triticale (25). Most QTL were detected in all four environments with similar additive effects, although some QTL showed a significant QTLenvironment interaction (Supplementary Table 6). To get a clear prediction about the contribution of the detected FHB-resistance QTL in improvement of the resistance level in each population, a distribution of the DH lines according to their number of FHBresistance QTL carried by each line was visualized by box plots (Fig. 3). Generally, the median was directed toward lower FHB index with an increasing number of QTL.

QTL analyses were also performed for plant height and heading stage. In all, 18 QTL were recorded for heading stage and 17 for plant height across the four populations.

\section{DISCUSSION}

Phenotypic data. The genetic material used in this study were four DH populations derived from four biparental crosses among six elite parents from a commercial triticale breeding program. The DH lines provided perfect homozygosity for QTL mapping, and seed production for multienvironmental trials was easily feasible. The parents did not differ much in their FHB resistance because highly susceptible parents are normally not used for further breeding. Basically, parents of the DH populations were moderately resistant compared with the most susceptible check 'Witon' with an FHB index of $37 \%$. Despite this, DH progenies showed a broad genetic variation, with FHB severities segregating from 13 to $51 \%$. Genotypic variances were significantly different from zero in all populations, with high entry-mean heritabilities of $h^{2} \geq 0.8$. These phenotypic data provide a reliable basis for QTL mapping.

Genetic architecture of FHB resistance in triticale. Phenotypic data of four mapping populations suggested a typical quantitative inheritance of FHB resistance in the field. This was confirmed by QTL analyses revealing three to five QTL per population that explained, together, 51 to $80 \%$ of genotypic variance. Hexaploid triticale has the advantage of combining both the A and $\mathrm{B}$ genomes of wheat and the $\mathrm{R}$ genome of rye. Consequently, we expect that QTL for FHB resistance reported from wheat should also be present in triticale. The comparison of QTL positions, however, is difficult because we used DArT markers whereas, in most previous wheat studies, simple-sequence repeat markers were used. Nevertheless, all wheat genomic regions found to be responsible for FHB resistance in our triticale study have already been assigned to FHB resistance in wheat $(8,44)$.

No QTL study for FHB resistance is known to us in rye. Therefore, the QTL on chromosomes 4R, 5R, and 7R are first reported here. Apart from the dwarfing locus $D d w 1$ on $5 \mathrm{R}$, the effects of the three rye-derived QTL ranged from 12 to $40 \%$ and, thus, had effects similar to those from wheat, illustrating the large contribution from rye for FHB resistance in triticale. In population C only, no QTL located on the rye genome was found. Genetic architecture of FHB resistance in triticale seems to be similar to that of wheat $(8,28,35)$. A large array of QTL, mostly with small to moderate effects, can be detected in European germplasm. They are mainly inherited additively and can be pyramided to obtain a better FHB resistance (Fig. 3). The fact that parental means closely resembled means of DH populations shows that not much epistasis was present in these populations.

TABLE 2. Means for the two parents (P1 and P2) and means, minimum, and maximum of Fusarium head blight (FHB) severity (\%) of four populations

\begin{tabular}{|c|c|c|c|c|c|c|}
\hline \multirow[b]{2}{*}{ Population } & \multicolumn{2}{|c|}{ Parents } & \multicolumn{4}{|c|}{ DH lines } \\
\hline & $\mathrm{P} 1$ & $\mathrm{P} 2$ & $N^{\mathrm{a}}$ & Mean & Minimum & Maximum \\
\hline A: Modus/Saka3006 & 26.2 & 20.4 & 131 & 26.6 & 14.7 & 48.8 \\
\hline B: Modus/Saka3008 & 26.2 & 35.3 & 120 & 30.3 & 16.5 & 51.1 \\
\hline C: HeTi 117-06/Pawo & 24.8 & 21.7 & 200 & 23.6 & 12.8 & 35.7 \\
\hline D: HeTi 117-06/Pigmej & 24.8 & 27.3 & 200 & 24.9 & 13.5 & 45.4 \\
\hline
\end{tabular}

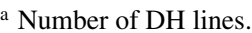

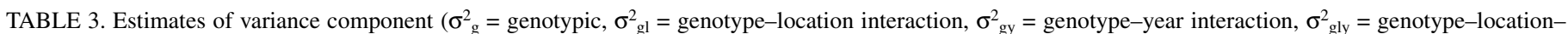

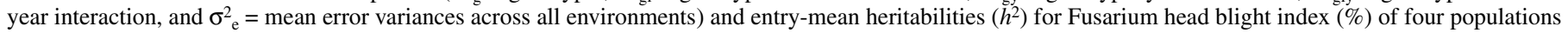

\begin{tabular}{|c|c|c|c|c|c|c|}
\hline \multirow[b]{2}{*}{ Population } & \multicolumn{5}{|c|}{ Variance components ${ }^{\mathrm{a}}$} & \multirow[b]{2}{*}{$h^{2}$} \\
\hline & $\sigma_{g}^{2}$ & $\sigma_{\mathrm{gl}}^{2}$ & $\sigma_{\text {gy }}^{2}$ & $\sigma_{\text {gly }}^{2}$ & $\sigma_{\mathrm{e}}^{2}$ & \\
\hline A: Modus/Saka3006 & $28.14 * * *$ & $3.43^{*}$ & $3.84 * *$ & $3.16^{*}$ & 30.61 & 0.80 \\
\hline B: Modus/Saka3008 & $53.15 * * *$ & $5.40 * *$ & $6.38 * *$ & $6.14 * * *$ & 30.61 & 0.84 \\
\hline C: HeTi 117-06/Pawo & $16.25 * * *$ & 0.64 & 0.57 & $3.40 * * *$ & 15.10 & 0.86 \\
\hline D: HeTi 117-06/Pigmej & $26.74 * * *$ & $1.77 *$ & $2.17 *$ & $6.33 * * *$ & 15.10 & 0.85 \\
\hline
\end{tabular}

a Asterisks: *,**, and *** indicate significant at $P<0.05,0.01$, and 0.001 , respectively.

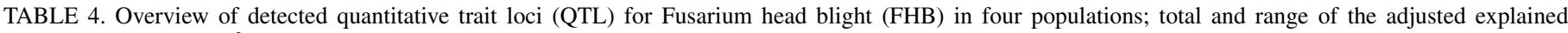
phenotypic variances $\left(R_{a d j}^{2}\right)$; and correlation of FHB with plant height (PH) and heading stage (HS), and FHB QTL with colocalization ${ }^{\mathrm{a}}$

\begin{tabular}{|c|c|c|c|c|c|c|c|}
\hline \multirow[b]{2}{*}{ Population } & \multirow[b]{2}{*}{$N$} & \multicolumn{2}{|c|}{$R_{a d j}^{2}$} & \multicolumn{2}{|c|}{ Correlation with FHB } & \multicolumn{2}{|c|}{ QTL with colocalization } \\
\hline & & Total & Range & PH & HS & PH & HS \\
\hline A: Modus/Saka3006 & 3 & 41.1 & $11.22-36.31$ & $-0.52 * * *$ & 0.04 & $\ldots$ & 1 \\
\hline B: Modus/Saka3008 & 5 & 67.5 & $10.92-36.54$ & $-0.28 * *$ & 0.09 & 1 & 2 \\
\hline C: HeTi 117-06/Pawo & 5 & 46.4 & $6.75-42.16$ & $-0.72 * * *$ & $-0.39 * * *$ & 1 & 1 \\
\hline D: HeTi 117-06/Pigmej & 4 & 45.4 & $6.09-40.32$ & $-0.76 * * *$ & $-0.55 * * *$ & 1 & 1 \\
\hline
\end{tabular}

a $N=$ number of QTL; $* *$ and $* * *$ indicate significant at $P<0.01$ and 0.001 , respectively. 
QTL in all populations were contributed by both parents, illustrating the importance of recombination. Thus, in three of four populations, the best progeny was significantly more resistant than the better parent (= transgression). The use of an integrated map as in our study has the advantage that QTL positions also can be directly compared among genetically nonrelated populations. Indeed, QTL found to be present in each of two populations were attributed to the common parents of these populations. In populations $\mathrm{A}$ and $\mathrm{B}$, three QTL on chromosomes $3 \mathrm{~B}, 4 \mathrm{R}$, and $5 \mathrm{R}$ were found to be common. The common QTL located on chromosome 3B could correspond with Fhbl, the FHB-resistance QTL frequently used in wheat breeding programs, but it is not likely because Fhbl has been found, to date, only in wheat of Asian origin (8). Alternatively, Buerstmayr et al. (8) described a second QTL on chromosome 3B near the centromere. The detected QTL on chromosome $4 \mathrm{R}$ is prominent, with a significant additive effect in both populations and large explained phenotypic variance $\left(R_{a d j}^{2}=\right.$ $34 \%$ ). In populations C and D, only one common QTL located on chromosome 2B contributed a small effect on FHB resistance. According to the significant interactions between genotypes and locations and years, some QTL also revealed a significant QTLenvironment interaction.

The QTL with large effects $\left(R^{2}{ }_{a d j} \geq 35 \%\right)$ detected in this study on chromosomes $6 \mathrm{~A}, 3 \mathrm{~B}$, and $4 \mathrm{R}$ need to be further validated.

Colocalization of QTL for FHB resistance, heading stage, and plant height. Several QTL for FHB resistances in wheat were found to overlap with QTL of plant height or heading stage $(17,21,45,47)$. In our study, five QTL for heading stage overlapped with FHB-resistance QTL across all populations. This result was not expected, because we corrected all FHB ratings for this morphological trait, indicating that there must be a nonlinear genetic linkage that has nothing to do with the phenological stage at infection itself. In two of four populations (C and D) with overlapping QTL for heading stage and FHB resistance, we observed highly significant phenotypic coefficients of correlation between both traits. No correlation was found in populations A and B; the absence of the correlation can be attributed to the small effect size for the heading stage QTL in both populations. Conversely, for plant height, significant correlations between FHB index and plant height were found in all populations, ranging from -0.3 to -0.8 , as indicated previously for wheat (29). Accordingly, QTL for plant height overlapped with FHB resistance QTL on chromosomes 2B, 6A, and 5R. However, there are two aspects of this correlation to be considered: (i) major height-reducing (dwarfing) genes that enhance FHB susceptibility $(23,25,34)$ and (ii) colocalization of QTL alleles for tallness and FHB resistance. Although the first aspect might have physiological causes based on the DELLA protein which represses gibberellic acid (GA) responsive growth (43), the second aspect is due to direct or indirect effects of height differences per se (10). As explanations, very different effects have been considered, from microclimatic differences between tall and short plants in the field (51) over pleiotropic or morphological effects such as effects of peduncle length and compactness of head to increased cell density of the short plants promoting Fusarium spread in the host tissue (29). Obviously, both aspects are important for long-strawed triticale.

We detected two QTL with strong effects not only on FHB resistance but also simultaneously on plant height and heading stage. On chromosome $5 \mathrm{R}$ in population $\mathrm{D}$, the major dwarfing gene $D d w 1$ is located (25), explaining $72 \%$ of phenotypic variation for plant height and having large effects on heading stage (64\%) and FHB index (40\%). This gene is GA sensitive (27) and, thus, not comparable with RhtBl and RhtDl dwarfing genes from wheat in this respect. A second QTL on chromosome 6A also
$5 A \quad 6 A \quad 2 B$

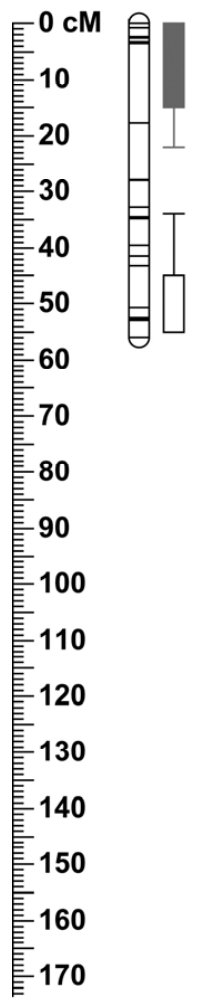

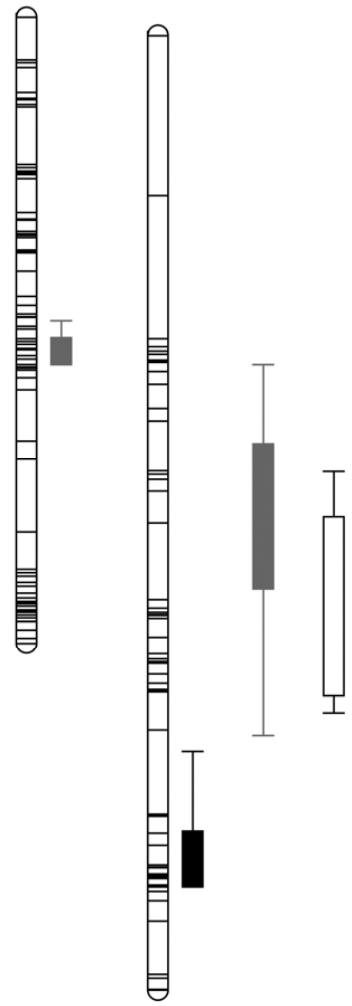

3B

4B

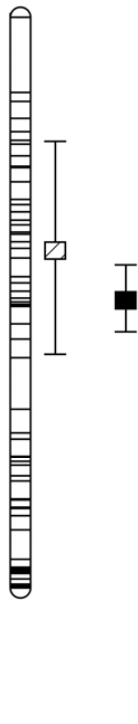

$5 R$

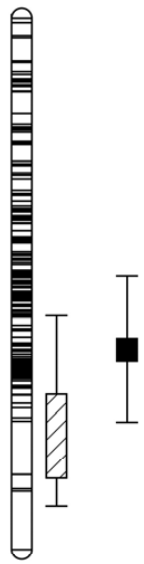

$7 R$
4R

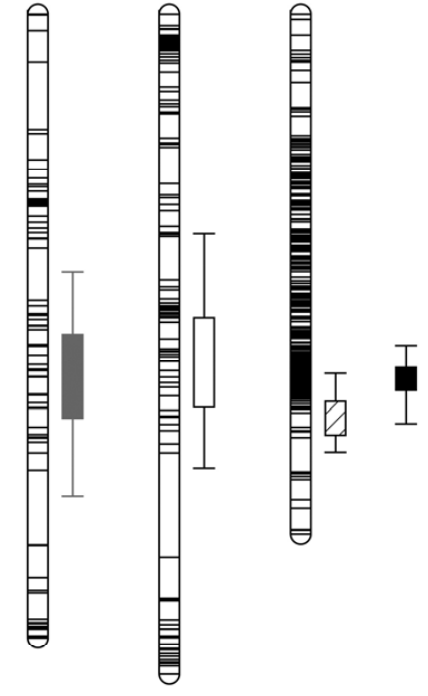

\section{A: Modus/Saka3006}

B: Modus/Saka3008

\section{C: HeTi 117-06/Pawo}

D: HeTi 117-06/Pigmej

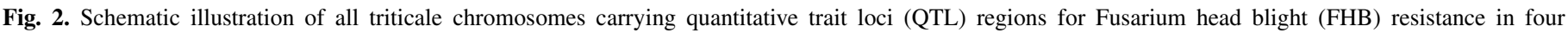
populations. 
affected all three traits in population C. An association between FHB resistance and plant height for a QTL with a similar map position was previously found by Haeberle et al. (21), reporting that the resistance-QTL allele reduced FHB index by $27 \%$ but increased plant height by $14 \mathrm{~cm}$. Similarly, in population C, FHB resistance QTL allele on chromosome 6A led to plants being approximately $11 \mathrm{~cm}$ taller. Additionally, this QTL delayed heading according to a meta-QTL for heading time at a similar position (20).

Use of FHB-resistant QTL alleles in practical breeding. Evaluating current breeding materials combining FHB resistance and favorable agronomic traits by a precise inoculation method and reliable field assessment is an essential procedure for an efficient resistant breeding program. Considering the quantitative nature of FHB resistance, the accumulation of different sources of resistance is necessary (4). Use of adapted germplasm has the advantage that the outcome can directly be considered for cultivar development. In our study, major and minor QTL for FHB resis- tance were detected from wheat and rye genomes, the latter presenting a totally new source of FHB resistance. Caused by the additive nature of FHB resistance (37), pyramiding of QTL from different parents in elite breeding populations seems promising (Fig. 3). The most prominent QTL for FHB resistance detected in this study on chromosomes $6 \mathrm{~A}, 3 \mathrm{~B}, 4 \mathrm{R}$, and $5 \mathrm{R}$ could be used for marker-assisted selection (MAS) after validation. Two of them (6A and 5R), however, showed simultaneously strong effects on plant height and heading stage, with resistant progenies being considerably taller and later. For the breeder, it is a challenging task to detect progenies possessing the resistance allele without these negative side effects (25). After crossing the resistance donors, MAS would be promising to select large triticale populations for the presence of one or more of the four mentioned resistance QTL alleles and to subsequently select for progenies with favorable agronomic traits in the field. This should accelerate selection for more FHB-resistant triticale cultivars to be used for healthy feed.
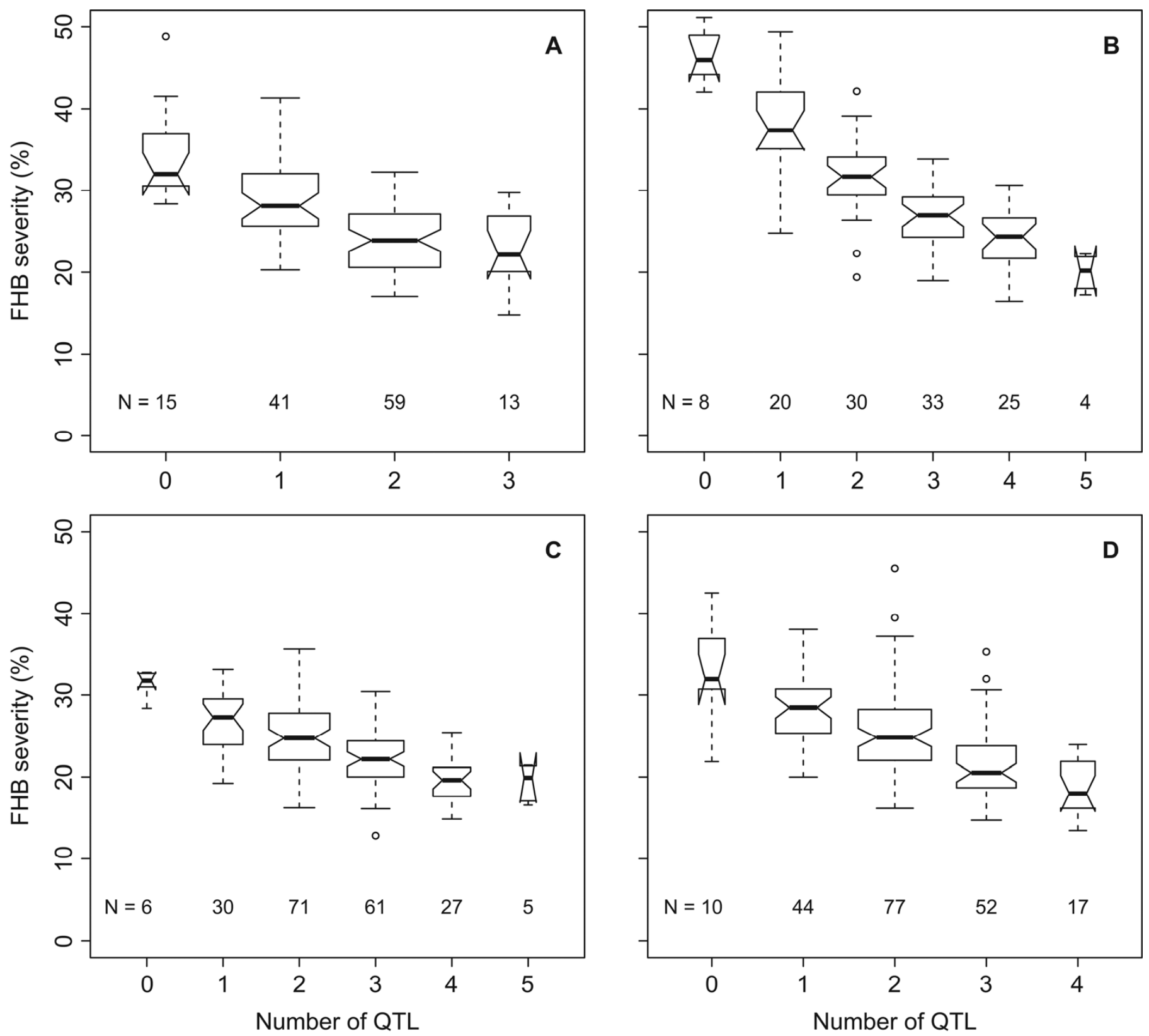

Fig. 3. Notched boxplots summarizing the distribution of doubled-haploid (DH) lines in each population (A, B, C, and $\mathbf{D})$ according to the different number of Fusarium head blight resistance quantitative trait loci (QTL) carried by each line; if notches do not overlap, this indicates that medians are different according to McGill et al. (30). $N=$ number of DH lines in each QTL class, horizontal line within boxes $=$ median, and $\mathrm{o}=$ outliers. 


\section{ACKNOWLEDGMENTS}

We thank G. Wahle, former SAKA GmbH \& Co.KG, for sharing parental lines of populations A and B; E. A. Weissmann, Saatzucht Dr. Hege GbR, Waldenburg, for sharing populations $\mathrm{C}$ and $\mathrm{D}$; teams at Hohenheim and Oberer Lindenhof for their excellent technical support; and L. Dahl and S. Michel for their work during their M.Sc. and B.Sc. theses, respectively. This research was partially funded by the German Federal Ministry of Education and Research (BMBF, grant number 0315414). R. Kalih gratefully acknowledges the grant from the German Academic Exchange Service (DAAD), Bonn.

\section{LITERATURE CITED}

1. Alheit, K. V., Reif, J. C., Maurer, H. P., Hahn, V., Weissmann, E. A., Miedaner, T., and Würschum, T. 2011. Detection of segregation distortion loci in triticale ( $\times$ Triticosecale Wittmack) based on a high-density DArT marker consensus genetic linkage map. BMC Genomics 12:380.

2. Anderson, J. A. 2007. Marker-assisted selection for Fusarium head blight resistance in wheat. Int. J. Food Microbiol. 119:51-53.

3. Anonymous. 2001. Growth stages of mono- and dicotyledonous plants. BBCH Monograph. Federal Biological Research Centre for Agriculture and Forestry. http://www.bba.de/veroeff/bbch/bbcheng.pdf

4. Bai, G. H., and Shaner, G. 2004. Management and resistance in wheat and barley to Fusarium head blight. Annu. Rev. Phytopathol. 42:135-161.

5. Bai, G. H., Shaner, G. E., and Ohm, H. W. 2000. Inheritance of resistance to Fusarium graminearum in wheat. Theor. Appl. Genet. 100:1-8.

6. Baierl, A., Bogdan, M., Frommlet and, F., and Futschik, A. 2006. On locating multiple interacting quantitative trait loci in intercross designs. Genetics 173:1693-1703.

7. Becher, R., Miedaner, T., and Wirsel, S. G. R. 2013. Biology, diversity, and management of FHB causing Fusarium species in small-grain cereals. Pages 199-241 in: The Mycota XI-Agricultural Applications, 2nd ed. F. Kempken, ed. Springer, Berlin, Heidelberg, Germany.

8. Buerstmayr, H., Ban, T., and Anderson, J. A. 2009. QTL mapping and marker-assisted selection for Fusarium head blight resistance in wheat: A review. Plant Breed. 128:1-26.

9. Bundessortenamt. 2013. Descriptive variety list. Cereal, maize, largegrained pulse crops, root crops (except potato). (In German) http://www.bundessortenamt.de/internet30/fileadmin/Files/PDF/bsl_getrei de_2013.pdf

10. Chen, G., Yan, W., Liu, y., Wei, Y., Zhou, M., Zheng, Y. L., Manners, J. M., and Liu, C. 2014. The non-gibberellic acid-responsive semi-dwarfing gene uzu affects Fusarium crown rot resistance in barley. BMC Plant Biol. 14:22.

11. Churchill, G., and Doerge, R. 1994. Empirical threshold values for quantitative trait mapping. Genetics 138:963-971.

12. Darvasi, A., and Soller, M. 1997. A simple method to calculate resolving power and confidence interval of QTL map location. Behav. Genet. 27:125-132.

13. Emrich, K., Wilde, F., Miedaner, T., and Piepho, H. P. 2008. REML approach for adjusting the Fusarium head blight rating to a phenological date in inoculated selection experiments of wheat. Theor. Appl. Genet. 117:65-73.

14. FAOSTAT, 2013. Production Crops. http://faostat.fao.org/site/567/ DesktopDefault.aspx?PageID=567\#ancor

15. Fehr, W. R. 1987. Principles of Cultivar Development, Vol. 1. Theory and Technique. Macmillan, New York.

16. Fisher, R. A. 1921. On the "probable error" of a coefficient of correlation deduced from a small sample. Metron 1:1-32.

17. Gervais, L., Dedryver, F., Morlais, J. Y., Bodusseau, V., Negre, S., and Bilous, M. 2003. Mapping of quantitative trait loci for field resistance to Fusarium head blight in an European winter wheat. Theor. Appl. Genet. 106:961-970.

18. Gilmour, A. R., Gogel, B. J., Cullis, B. R., and Thompson, R. 2009. ASReml User Guide Release 3.0.VSN International Hemel Ltd., Hempstead, UK. http://www.vsni.co.uk

19. Gowda, M., Hahn, V., Reif, J. C., Longin, C. F. H., Alheit, K., and Maurer, H. P. 2011. Potential for simultaneous improvement of grain and biomass yield in Central European winter triticale germplasm. Field Crops Res. 121:153-157.

20. Griffiths, S., Simmonds, J., Leverington, M., Wang, Y., Fish, L., Sayers, L., Alibert, L., Orford, S., Wingen, L., Herry, L., Faure, S., Laurie, D., Bilham, L., and Snape, J. 2009. Meta-QTL analysis of the genetic control of ear emergence in elite European winter wheat germplasm. Theor. Appl. Genet. 119:383-395.

21. Haeberle, J., Schmolke, M., Schweizer, G., Korzun, V., Ebmeyer, E., Zimmermann, G., and Hartl, L. 2007. Effects of two major Fusarium head blight resistance QTL verified in a winter wheat backcross population.
Crop Sci. 47:1823-1831

22. Haley, C. S., and Knott, S. A. 1992. A simple regression method for mapping quantitative trait loci in line crosses using flanking markers. Heredity 69:315-324.

23. Hilton, A. J., Jenkinson, P., Hollins, T. W., and Parry, D. W. 1999. Relationship between cultivar height and severity of Fusarium ear blight in wheat. Plant Pathol. 48:202-208.

24. John, J. A., and Williams, E. R. 1995. Cyclic and Computer-Generated Designs. Chapman \& Hall, London.

25. Kalih, R., Maurer, H. P., Hackauf, B., and Miedaner, T. 2014. Effect of a rye dwarfing gene on plant height, heading stage, and Fusarium head blight in triticale ( $\times$ Triticosecale Wittmack). Theor. Appl. Genet. 127:1527-1536.

26. Klahr, A., Zimmermann, G., Wenzel, G., and Mohler, V. 2007. Effects of environment, disease progress, plant height and heading date on the detection of QTLs for resistance to Fusarium head blight in an European winter wheat cross. Euphytica 154:17-28.

27. Korzun, V., Melz, G., and Börner, A. 1996. RFLP mapping of the dwarfing $(D d w 1)$ and hairy peduncle $(H p)$ genes on chromosome 5 of rye (Secale cereale L.). Theor. Appl. Genet. 92:1073-1077.

28. Loeffler, M., Schon, C. C., and Miedaner, T. 2009. Revealing the genetic architecture of FHB resistance in hexaploid wheat (Triticum aestivum L.) by QTL meta-analysis. Mol. Breed. 23:473-488.

29. Mao, S. L., Wei, Y. M., Cao, W., Lan, X. J., Yu, M., Chen, Z. M., Chen, G. Y., and Zheng, Y. L. 2010. Confirmation of the relationship between plant height and Fusarium head blight resistance in wheat (Triticum aestivum L.) by QTL meta-analysis. Euphytica 174:343-356.

30. McGill, R., Tukey, J. W., and Larsen, W. A. 1978. Variations of box plots. Am. Stat. 32:12-16.

31. Mesterházy A., Bartok T., Mirocha, C. G., and Komoroczy, R. 1999. Nature of wheat resistance to Fusarium head blight and the role of deoxynivalenol for breeding. Plant Breed. 118:97-110.

32. Miedaner, T., Gang, G., and Geiger, H. H. 1996. Quantitative-genetic basis of aggressiveness of 42 isolates of Fusarium culmorum for winter rye head blight. Plant Dis. 80:500-504.

33. Miedaner, T., Schneider, B., and Oettler, G. 2006. Means and variances for Fusarium head blight resistance of F2-derived lines from winter triticale and winter wheat crosses. Euphytica 152:405-411.

34. Miedaner, T., and Voss, H. H. 2008. Effect of dwarfing Rht genes on Fusarium head blight resistance in two sets of near-isogenic lines of wheat and check cultivars. Crop Sci. 48:2115-2122.

35. Miedaner, T., Würschum, T., Maurer, H. P., Korzun, V., Ebmeyer, E., and Reif, J. C. 2011. Association mapping for Fusarium head blight resistance in European soft winter wheat. Mol. Breed. 28:647-655.

36. Oettler, G. 2005. The fortune of a botanical curiosity-Triticale: Past, present and future. J. Agric. Sci. 143:329-346.

37. Oettler, G., Heinrich, N., and Miedaner, T. 2004. Estimates of additive and dominance effects for Fusarium head blight resistance of winter triticale. Plant Breed. 123:525-530.

38. Oettler, G., and Wahle, G. 2001. Genotypic and environmental variation of resistance to head blight in triticale inoculated with Fusarium culmorum. Plant Breed. 120:297-300.

39. Piepho, H. P., Williams, E. R., and Fleck, M. 2006. A note on the analysis of designed experiments with complex treatment structure. HortScience 41:446-452.

40. Pronyk, C., and Mazza, G. 2011. Optimization of processing conditions for the fractionation of triticale straw using pressurized low polarity water. Bioresour. Technol. 102:2016-2025.

41. R Development Core Team. 2012. R: A Language and Environment for Statistical Computing. http://www.r-project.org

42. Salmon, D. F., Mergoum, M., and Gómez-Macpherson, H. 2004. Triticale production and management. Pages 27-36 in: Triticale Improvement and Production. Food and Agriculture Organization of the United Nations, Rome.

43. Saville, R. J., Gosman, Burt, C. J., Makepeace, J., Steed, A., Corbitt, M., Chandler, E., Brown, J. K. M., Boulton, and Nicholson, P. 2012. The 'Green Revolution' dwarfing genes play a role in disease resistance in Triticum aestivum and Hordeum vulgare. Exp. Bot. $63: 1271-1283$.

44. Schmolke, M., Zimmermann, G., Buerstmayr, H., Schweizer, G., Miedaner, T., Korzun, V., Ebmeyer, E., and Hartl, L. 2005. Molecular mapping of Fusarium head blight resistance in the winter wheat population Dream/Lynx. Theor. Appl. Genet. 111:747-756.

45. Schmolke, M., Zimmermann, G., Schweizer G., Miedaner, T., Korzun, V., Ebmeyer, E., and Hartl, L. 2008. Molecular mapping of quantitative trait loci for field resistance to Fusarium head blight in a European winter wheat population. Plant Breed. 127:459-464.

46. Snijders, C. H. A., and Perkowski, J. 1990. Effects of head blight caused by Fusarium culmorum on toxin content and weight of wheat kernels. Phytopathology 80:566-570.

47. Steiner, B., Lemmens, M., Griesser, M., Scholz, U., Schondelmaier, J., 
and Buerstmayr, H. 2004. Molecular mapping of resistance to Fusarium head blight in the spring wheat cultivar Frontana. Theor. Appl. Genet. 109:215-224

48. Stram, D. O., and Lee, J. W. 1994. Variance components testing in the longitudinal mixed model. Biometrics 50:1171-1177.

49. Utz, H. F. 2012. PlabMQTL-Software for meta-QTL Analysis with Composite Interval Mapping, Version 0.5s. PlabMQTL Manual. Institute of Plant Breeding, Seed Science, and Population Genetics, Stuttgart, Germany. 50. Walker, A. S., Bouguennec, A., Confais, J., Morgant, G., and Leroux, P.
2011. Evidence of host-range expansion from new powdery mildew (Blumeria graminis) infections of triticale $(\times$ Triticosecale $)$ in France. Plant Pathol. 60:207-220.

51. Yan, W., Li, H., Cai, S., Ma, H., Rebetzke, G., and Liu, C. 2011. Effects of plant height on type I and type II resistance to Fusarium head blight in wheat. Plant Pathol. 60:506-512.

52. Yuen, G. Y., and Schoneweis, S. D. 2007. Strategies for managing Fusarium head blight and deoxynivalenol accumulation in wheat. J. Food Microbiol. 119:126-130. 